\title{
The content of glycogen phosphorylase and glycogen in preparations of sarcoplasmic reticulum-glycogenolytic complex is enhanced in diabetic rat skeletal muscle
}

\author{
E. Garduño, M. Nogues, J. M. Merino, C. Gutiérrez-Merino, F.Henao \\ Department of Biochemistry and Molecular Biology, Faculty of Sciences, University of Extremadura, Badajoz, Spain
}

\begin{abstract}
Aims/hypothesis. We have examined the effect of diabetes and pharmacological insulin treatment on the content of glycogen phosphorylase and glycogen associated with the sarcoplasmic reticulum-glycogenolytic complex from rat skeletal muscle.

Methods. Diabetes was induced in rats by streptozotocin injection. Enzymatic activities were measured using spectrophotometric methods. Glycogen phosphorylase was determined measuring the pyridoxal$5 '$-phosphate content and using polyacrylamide gel electrophoresis. Glycogen content was measured by enzymatic and the phenol sulfuric methods.

Results. The content of glycogen phosphorylase associated with the sarcoplasmic reticulum glycogenolytic complex gradually arises after diabetes induction. The content of glycogen phosphorylase was restored to a control value by pharmacological insulin treatment. In addition, the content of glycogen in preparations of sarcoplasmic reticulum-glycogenolytic complex of diabetic animals was also increased, whereas
\end{abstract}

the content of glycogen in total muscle of diabetic rats was similar to that of the control rats. The absolute and relative amount of glycogen associated with sarcoplasmic reticulum seemed to increase in diabetic animals. These effects on the compartmentalisation of glycogen were suppressed by insulin treatment. Additionally, the rate of conversion of glycogen phosphorylase $\mathrm{b}$ to $\mathrm{a}$, an index of the phosphorylase kinase activity, was $50 \%$ lower in diabetic rats, increasing the dephosphorylated form of glycogen phosphorylase and, as a consequence, its association with sarcoplasmic reticulum membranes.

Conclusion/interpretation. These results suggest that under diabetic conditions, both glycogen phosphorylase and a small percentage of muscle glycogen are relocalized in the sarcoplasmic reticulum-glycogenolytic complex. [Diabetologia (2001) 44: 12381246]

Keywords Skeletal muscle, glycogen phosphorylase, diabetes, insulin, rat, sarcoplasmic reticulum-glycogenolytic complex.
Received: 5 April 2001 and in revised form: 11 June 2001

Corresponding author: Dr. Fernando Henao, Departamento de Bioquímica y Biología Molecular, Facultad de Ciencias, Universidad de Extremadura, Avda. de Elvas, s/n, 06080-Badajoz, Spain. E-mail: fhenao@unex.es

Abbreviations: SR, Sarcoplasmic reticulum; SR-GL, sarcoplasmic reticulum - glycogenolytic complex; STZ, streptozotocin; Ap5A, $\mathrm{P}^{1}, \mathrm{P}^{5}$-di-(adenosine-5') pentaphosphate; EGTA, [ethylene-bis(oxyethylenenitrilo)]tetraacetic acid; PMSF, phenylmethylsulfonyl fluoride; EDTA, ethylenediaminetetraacetic acid; G6PDH, glucose-6-phosphate dehydrogenase; PGM, phosphoglucomutase ( $\alpha$-D-glucose-1,6-phosphomutase, EC 5.4.2.2.); A23187, calcimycin; PP1, protein phosphatase 1; PLP, pyridoxal 5'-phosphate; TES, 2-\{[2-hydroxy-1,1-bis(hydroxymethyl) ethyl]amino ethanesulfonic acid; I.U., $\mu$ mols of substrate per minute per mg of protein
Glycogen stored in skeletal muscle is a major stock for metabolic fuel in the body. The glycogen concentrations in skeletal muscle are tightly regulated by insulin via a signalling mechanism involving phosphorylation-dephosphorylation of many enzymes. Glycogen phosphorylase and glycogen synthase are the two key regulatory enzymes that catalyse the rate-limiting step of glycogen degradation and synthesis, respectively. Insulin and other hormones together regulate the activity of these two enzymes $[1,2]$.

Animals can be rendered diabetic by injecting streptozotocin or alloxan, a treatment that destroys the insulin-producing pancreatic cells. These animals with Type I (insulin-dependent) diabetes mellitus, 
which no longer produce insulin in response to food intake, have been used extensively in studies on the effects of insulin in the regulation of glycogen synthase and phosphorylase [3-5]. Insulin-activates glycogen synthesis in the insulin-responsive tissues of animals, namely skeletal muscle, liver and adipose tissues. This is achieved by an insulin-activated signal transduction kinase cascade that results in the dephosphorylation and hence activation of glycogen synthase, leading to an increase in the rate of glycogen deposition in insulin-responsive tissues in animals and humans [6-9]. Defects in the deposition of glycogen and the regulation of glycogen synthesis in the liver of severely insulin-deficient rats can be reversed in vivo after insulin administration [10].

Of interest, we and others have reported that several key enzymes regulating carbohydrate metabolism are associated with the sarcoplasmic reticulum $(\mathrm{SR})^{1}$ from skeletal muscle [11-14]. The association of glycogen particles with SR from skeletal muscle has been described previously and using subcellular fragmentation, isolation of sarcoplasmic reticulum-glycogenolytic complex (SR-GL) from rabbit and rats has been done [15-19]. We have suggested that these enzymes, in particular glycogen phosphorylase, can be located at this region of the cell because they provide a nearby source of energy for the SR $\mathrm{Ca}^{2+}$-ATPase, which plays a crucial part in sequestering cytosolic calcium to the SR membranes. This mechanism ensures the maintenance of low cytosolic $\mathrm{Ca}^{2+}$ concentrations, particularly relevant in physiological situations in which the AMP concentration of sarcoplasm is raised $[18,19]$. In this contest, indirect evidence has shown that SR vesicles isolated from cardiac and skeletal muscle contain a series of bound glycolytic enzymes and the addition of substrates and cofactors of these enzymes results in endogenous ATP production and $\mathrm{Ca}^{2+}$ uptake by SR [20]. More recently, ultrastructural evidence showed that glycolytic enzymes are associated with SR membranes and located near the SR $\mathrm{Ca}^{2+}$-ATPase [21].

Because the association of glycogen phosphorylase with SR-GL is important we aimed to determine if the association of glycogen phosphorylase with SRGL can be affected in an altered physiological condition such as Type I diabetes. We examined the content of glycogen phosphorylase in SR-GL prepared from skeletal-muscle obtained from streptozotocintreated diabetic rats, with and without pharmacological insulin treatment.

\section{Materials and methods}

Animal care and diabetes induction. Male rats (Wistar $325 \pm 5$ g) were made diabetic by a single intraperitoneal injection of streptozotocin (STZ) $\left(65 \mathrm{mg} \cdot \mathrm{kg}^{-1}\right.$ body weight) dissolved in $100 \mathrm{mmol} / \mathrm{l}$ sodium citrate $\mathrm{pH}=4.5$. Control rats were injected with the same volume of citrate buffer. After the injection of STZ the rats were fed ad libitum and were killed at different times as indicated in the Figure legends. After 3 days of STZ treatment the rats were screened for diabetes using blood glucose measurement with a 'One Touch System' (Lifescan, Johnson and Johnson C. Milpitas, Calif., USA) and showed a high concentration of glucose in blood $(21 \pm 4.5 \mathrm{mmol} / \mathrm{l})$ and significant weight loss $(>25 \mathrm{~g})$. Some diabetic rats were injected daily, subcutaneously with 3 I. U./100 g NPH insulin (Insulatard NPH. Novo Nordisk A/S 2880 Bagsvaerd, Denmark) to the end of the experiment (day 15 after STZ treatment). We measured the concentration of glucose in blood in diabetic insulin-treated rats to ensure adequate insulin replacement on a daily basis. Animal care followed the international regulations of laboratory animal care and handling approved by the University of Extremadura.

Preparation of sarcoplasmic reticulum-glycogenolytic complex. SR-GL was prepared from skeletal muscle of control, STZ-induced diabetic and insulin-treated STZ-induced diabetic male Wistar rats, following the protocol described [16] with slight modifications. Briefly, the muscle from the hind legs, about 60 to $80 \mathrm{~g}$ per three rats, was removed and placed in ice. The muscle was minced, divided in $20 \mathrm{~g}$ batches and homogenized with three pulses of $15 \mathrm{~s}$ each using an Ultra-Turrax T25 at $24000 \mathrm{rpm} \mathrm{min}{ }^{-1}$ in three volumes of Buffer A $(10 \mathrm{mmol} / 1$ Imidazol $\mathrm{pH}, 7.4,0.1 \mathrm{~mol} / \mathrm{l} \mathrm{KCl}, 0.3 \mathrm{~mol} / \mathrm{l}$ glycerol, $2 \mathrm{mmol} / \mathrm{l} \beta$ mercaptoethanol, $0.1 \mathrm{mmol} / \mathrm{l} \mathrm{PMSF}$ ). The suspension was centrifuged at $5000 \cdot \mathrm{g}$ for $20 \mathrm{~min}$ at $4{ }^{\circ} \mathrm{C}$. The pellet was discarded and the supernatant was strained through two layers of gauze, the $\mathrm{pH}$ was readjusted at 7.4 and centrifuged at $8.000 \cdot \mathrm{g}$ for $20 \mathrm{~min}$ at $4{ }^{\circ} \mathrm{C}$. The supernatant was strained through gauze, the $\mathrm{pH}$ adjusted at 7.4 and centrifuged at $100000 \cdot \mathrm{g}$ for 35 min at $4{ }^{\circ} \mathrm{C}$. The supernatant was discarded by aspiration and the pellet was resuspended in Buffer B containing $50 \mathrm{mmol} / \mathrm{l}$ Tes-KOH pH, 7.4, $0.1 \mathrm{~mol} / \mathrm{l} \mathrm{KCl}, 20 \%$ glycerol.

The procedure of isolation of SR-GL in the presence of protein phosphatase inhibitors was done in the same buffers described above with the following differences: Buffer A plus $50 \mathrm{mmol} / 1 \mathrm{NaF}, 10 \mathrm{mmol} / 1$ sodium pyrophosphate, $20 \mathrm{mmol} / \mathrm{l}$ $\beta$-glycerophosphate, $2 \mathrm{mmol} / \mathrm{l}$ EDTA and $2 \mathrm{mmol} / 1$ EGTA, and Buffer B plus $50 \mathrm{mmol} / \mathrm{l} \mathrm{NaF}, 10 \mathrm{mmol} / \mathrm{l}$ sodium pyrophosphate and $20 \mathrm{mmol} / \mathrm{l} \beta$-glycerophosphate.

Preparation of $S R$ vesicles and glycogen phosphorylase. The SR vesicles and glycogen phosphorylase from rabbit skeletal muscle were prepared for analytical comparison with SR-GL, as described $[22,23]$.

Analytical procedures. The protein concentration was measured using the Lowry method [24], with bovine serum albumin as the standard.

Serum insulin concentrations were measured with an insulin RIA kit (Coat-A-Count Insulin procedure. DPC 5700 West 96th Street. Los Angeles, Calif., USA).

The content in glycogen phosphorylase of our SR-GL preparations was determined measuring the PLP concentration after removing the enzyme by treatment with perchloric acid following the method described [11,25]. The glycogen content of SR-GL preparations has been measured following the phenol sulphuric method [26]. The glycogen content in muscle tissue was determined as described [27] with slight modifications. Briefly, the muscle tissue was first lyophilized, less than $5 \mathrm{mg}$ of lyophilized muscle tissue was deposited in a tube containing $0.5 \mathrm{ml}$ of $5.4 \mathrm{~mol} / 1 \mathrm{KOH}$ and heated at $100^{\circ} \mathrm{C}$ in a water bath during $15 \mathrm{~min}$ and shaken occasionally. The tubes were cooled in ice, the $\mathrm{pH}$ was adjusted at 7.0 by adding $0.2 \mathrm{ml}$ of buffer 
$1 \mathrm{~mol} / \mathrm{l} \mathrm{Mops-Tris} \mathrm{pH} 7.0$ and $2 \mathrm{~mol} / \mathrm{l} \mathrm{HCl}$, and finally the volume was adjusted to $10 \mathrm{ml}$ by adding water. $0.5 \mathrm{ml}$ of glycogen standards (solution of glycogen in water) or samples, were mixed with $0.3 \mathrm{ml}$ of $10 \mathrm{mmol} / \mathrm{l}$ acetate buffer $\mathrm{pH} 4.8$ and incubated with $0.05 \mathrm{U}$ of amyloglucosidase during $30 \mathrm{~min}$ at $25^{\circ} \mathrm{C}$. $1.42 \mathrm{ml}$ of assay medium was added to each sample and samples were incubated during $30 \mathrm{~min}$ at $25^{\circ} \mathrm{C}$. The samples were centrifuged during $10 \mathrm{~min}$ at $1500 \cdot \mathrm{g}$ and the absorbance of the supernatant was measured at $340 \mathrm{~nm}$. The glycogen concentration was determined by interpolation to a calibration curve made with standards. Control experiments were made without amyloglucosidase. The assay medium contained $86 \mathrm{mmol} / \mathrm{l}$ Tris- $\mathrm{HCl}$ $\mathrm{pH} 7.9,0.7 \mathrm{mmol} / 1 \mathrm{MgCl}_{2}, 0.07 \mathrm{mmol} / 1 \mathrm{NADP}^{+}, 0.5 \mathrm{IU}$ hexokinase, $1 \mathrm{IU}$ G6PDH and $0.35 \mathrm{mmol} / \mathrm{l}$ ATP.

The $\mathrm{Ca}^{2+}$-ATPase activity was measured as indicated in [28]. The F1-ATPase activity was measured in the presence of $5 \mathrm{mmol} / \mathrm{l}$ of sodium azide. To determine glycogen phosphorylase, PGM and hexoquinase enzyme activities, we have used the same medium described in [19]. Creatine kinase, myokinase and AMP-deaminase activities were measured as indicated [11].

Polyacrylamide gel electrophoresis was done according to a method reported previously [29].

Measurement of the rate of conversion of glycogen phosphorylase $b$ to $a$. It has been shown that phosphorylase kinase converts glycogen phosphorylase from the b form to the active glycogen phosphorylase a by phosphorylation of one specific serine residue of each of the two identical subunits in a process that requires ATP [30]. It has been shown that phosphorylase kinase is associated with SR membranes isolated from rabbit [31] and from mouse skeletal muscle [32]. This kinase might play a part in regulating $\mathrm{Ca}^{2+}$ transport [31]. The method to measure phosphorylase kinase activity is based on determining the formed glycogen phosphorylase a [33, 34].

To measure the rate of transformation of glycogen phosphorylase $b$ to $a$, which is an index of phosphorylase kinase present in SR-GL, we have used the experimental approach indicated in [16]. Our preparations of SR-GL contain endogenous myokinase activity (see Results) which can result in a considerable AMP formation from ADP produced in the assay medium. This AMP can be used by glycogen phosphorylase $b$ present in our preparations and can alter the results of measurements of the rate of conversion of glycogen phosphorylase b to a. We therefore optimized two aspects of our experimental protocol to minimize the AMP production whereby we added to the assay medium: (i) the coupled enzyme system pyruvate kinase-lactate dehydrogenase as an ATP regenerating system, and (ii) $\mathrm{Ap}_{5} \mathrm{~A}$, a potent inhibitor of myokinase activity.

To determine the kinetic parameter of glycogen phosphorylase $\mathrm{b} \rightarrow \mathrm{a}$ conversion, the experiments were carried out as indicated in Figure 1 at $30^{\circ} \mathrm{C}$ in a medium containing $50 \mu \mathrm{g} /$ $\mathrm{ml}$ of SR-GL, $20 \mathrm{mmol} / \mathrm{l}$ Mes-KOH (pH 7), $10 \mathrm{mmol} / \mathrm{l}$ $\mathrm{MgCl}_{2}, 15 \mathrm{mmol} / 1 \mathrm{KH}_{2} \mathrm{PO}_{4}, 0.1 \mathrm{mmol} / \mathrm{l} \mathrm{CaCl}_{2}, 1 \mathrm{mmol} / \mathrm{l} \beta$ mercaptoethanol, $\quad 0.05 \mathrm{mmol} / \mathrm{l}$ glucose-1,6-bisphosphate, $2.5 \mathrm{mg} / \mathrm{ml}$ glycogen, $0.05 \mathrm{mmol} / \mathrm{A} \mathrm{Ap}_{5} \mathrm{~A}, 2.5 \mathrm{mmol} / \mathrm{l}$ phosphoenolpyruvate, $0.5 \mathrm{mmol} / \mathrm{l} \mathrm{NADP}+, 7.5 \mathrm{IU}$ pyruvate kinase, 5 IU phosphoglucomutase, 5 IU glucose-6-phosphate dehydrogenase, $2 \mu \mathrm{g} / \mathrm{ml}$ calcimycin. After adding SR-GL to the assay medium we observed a little slope which reflected the glycogen phosphorylase a activity in our preparations of SR-GL. The arrow indicates the addition of $2 \mathrm{mmol} / \mathrm{l}$ ATP. In these conditions, we can obtain the rate of glycogen phosphorylase $\mathrm{b} \rightarrow \mathrm{a}$ conversion (we have registered this curve during a period of 5 to $20 \mathrm{~min}$ depending on the amount of protein added to the assay medium). At the end of each experiment $1 \mathrm{mmol} / \mathrm{l}$ AMP was added to evaluate the total glycogen phosphorylase activity. $\mathrm{V}_{\mathrm{m}}$ can be calculated as the rate of glucose-1-P production ( $\mu \mathrm{mol}$ glucose-1-P/min) in $1 \mathrm{mmol} / \mathrm{l}$ AMP and $\mathrm{a}_{0}$ as the rate of glucose-1-P production in the $\mathrm{ab}-$ sence of ATP in per cent with respect to $V_{m}$. The presence in the assay medium of the coupled enzyme system PGMG6PDH ensures that the glucose-1-P production can be related directly to the production of NADPH by reducing $\mathrm{NADP}^{+}$, measured at $340 \mathrm{~nm}$. For this experimental approach we used PGM and G6PDH $\left(\mathrm{NH}_{4}\right)_{2} \mathrm{SO}_{4}$-free because we noticed that the presence of $\left(\mathrm{NH}_{4}\right)_{2} \mathrm{SO}_{4}$ inhibits the rate of conversion of glycogen phosphorylase $b$ to $\mathrm{a}$.

After ATP additions the experimental kinetic data obtained can fit the following equation:

$\frac{\mathrm{d}[\text { glucose }-1-\mathrm{P}]}{\mathrm{dt}}=\mathrm{V}_{\mathrm{m}}\left(\mathrm{a}_{0}+\Delta \mathrm{a} \cdot \mathrm{t}\right)$

where $\mathrm{t}$ and $\Delta \mathrm{a}$ are the time and the rate of glycogen phosphorylase $\mathrm{b} \rightarrow \mathrm{a}$ conversion in per cent with respect to $\mathrm{V}_{\mathrm{m}}$, respectively. Operating in equation (1)

$\mathrm{d}$ [glucose-1-P] $=\left(\mathrm{V}_{\mathrm{m}} \cdot \mathrm{a}_{0}+\mathrm{V}_{\mathrm{m}} \cdot \Delta \mathrm{a} \cdot \mathrm{t}\right) \mathrm{dt}$

[glucose-1-P] $]_{\mathrm{t}}=\mathrm{V}_{\mathrm{m}} \cdot \mathrm{a}_{0} \cdot \mathrm{t}+1 / 2 \cdot \mathrm{V}_{\mathrm{m}} \cdot \Delta \mathrm{a} \cdot \mathrm{t}^{2}$

where $[\text { glucose-1-P }]_{t}$ is the concentration of glucose-1-P at a defined time.

We can obtain (with experiments as that shown in Fig. 1) all the parameters of equation (3) except $\Delta$ a. However, this parameter can be calculated by fitting the experimental results with an Inplot Software (GraphPAD Software, San Diego, Calif., USA) using the following polynomial equation:

$[\text { glucose }-1-\mathrm{P}]_{\mathrm{t}}=\mathrm{B} \cdot \mathrm{t}+\mathrm{C} \cdot \mathrm{t}^{2}$

where

$\mathrm{a}_{0}=\mathrm{B} / \mathrm{V}_{\mathrm{m}}(5)$

and

$\Delta \mathrm{a}=2 \mathrm{C} / \mathrm{V}_{\mathrm{m}}$

The value of $\Delta \mathrm{a}$ is the per cent of glycogen phosphorylase $\mathrm{b}$ that is transformed in glycogen phosphorylase a per min.

Statistical analysis. A $p$ value of less than 0.05 was considered statistically significant.

\section{Results}

Parameters of the rats used in this study are summarized in Table 1 . Diabetes induction by intraperitoneal STZ injection caused a weight loss, particularly visible in the muscle of the hind legs of the rats during a 15 day period (mean mass of the hind muscle was $25 \mathrm{~g}$ in control rats and $16 \mathrm{~g}$ in diabetic rats). These rats were hyperglycaemic and showed a decrease in the concentrations of plasma insulin. Insulin treatment of STZ-induced diabetic rats lowered the glucose concentrations in blood, and showed similar values to those for control rats. The weight of the rats restored to a normal value and an increase of the lipogenesis is clearly visible in these animals. Of note, 
Table 1. Body weight, concentration of glucose in blood and plasma insulin of normal, STZ-induced diabetic and STZ-induced insulin-treated diabetic rats used for SR-GL preparations

\begin{tabular}{llcc}
\hline & Body weight $(\mathrm{g})$ & Blood glucose $(\mathrm{mmol} / \mathrm{l})$ & Plasma insulin $(\mu \mathrm{IU} / \mathrm{ml})$ \\
\hline Control $(n=49)$ & $325 \pm 5$ & $3.66 \pm 0.07$ & $18.5 \pm 4.8$ \\
STZ (diabetic) $(n=30)$ & $265 \pm 5$ & $25.40 \pm 1.15$ & $5.9 \pm 0.8$ \\
STZ + Insulin $(n=12)$ & $367 \pm 8$ & $3.88 \pm 0.26$ & $240 \pm 59.2$ \\
\hline
\end{tabular}

The number of animals used for each measurement is indicated in brackets. All values are the means \pm SEM

Table 2. Enzyme activities ${ }^{\mathrm{a}}$ of preparations of sarcoplasmic reticulum-glycogenolytic complex from skeletal muscle of normal and diabetic rats

\begin{tabular}{lcc}
\hline & \multicolumn{2}{l}{$\begin{array}{l}\mu \text { mol substrate/min } \cdot \mathrm{mg} \text { SR-GL } \\
\text { protein }\end{array}$} \\
\cline { 2 - 3 } & Control & STZ-induced diabetes \\
\hline AMP-deaminase & $0.07 \pm 0.01$ & $0.08 \pm 0.02$ \\
$\mathrm{Mg}^{2+}$-ATPase $\mathrm{Ca}^{2+}-$ & $0.76 \pm 0.15$ & $0.44 \pm 0.08$ \\
independent & $3.33 \pm 0.24$ & $2.49 \pm 0.29$ \\
$\mathrm{Ca}^{2+}$-dependent & $0.40 \pm 0.06$ & $0.22 \pm 0.04$ \\
F1-ATPase & $0.44 \pm 0.04$ & $0.49 \pm 0.03$ \\
Creatine kinase & $0.34 \pm 0.06$ & $3.83 \pm 0.46$ \\
Glycogen phosphorylase & \\
Myokinase & $0.53 \pm 0.06$ & $0.55 \pm 0.05$ \\
Phosphoglucomutase & $0.017 \pm 0.004$ & $0.018 \pm 0.002$ \\
\hline
\end{tabular}

${ }^{\mathrm{a}}$ Data are the means $\pm \operatorname{SEM}(n>30)$

${ }^{\mathrm{b}} p<0.001$, the difference among the group means is very significant. $p$ values were obtained by ANOVA

the insulin concentrations in the plasma of STZ-induced diabetic rats treated with a pharmacological dose of insulin, are extremely high, at the expense of excessive weight gain and fat deposition. Thus, the insulin treatment is a response to excessive insulin (hyperinsulinaemia).

Table 2 lists the most relevant enzyme activities measured in SR-GL membrane preparations obtained from normal and STZ-induced diabetic rats. These results show that in SR-GL preparations from rat skeletal muscle there are different activities of non-transmembrane enzymes associated with SRGL preparations, consistent with our earlier results obtained with SR membranes from rabbit skeletal muscle [11]. AMP-deaminase, creatine kinase, myokinase and PGM activities in SR-GL membranes did not show differences between control and diabetic rats. As an index of mitochondrial contamination, the F1-ATPase activity in SR-GL membranes is clearly lower in diabetic rats. With ATPase activities, the values of $\mathrm{Ca}^{2+}$-independent and $\mathrm{Ca}^{2+}$-dependent ATPase activities are lower in diabetic rats. The main difference between control and diabetic rats was found in the total glycogen phosphorylase activity, with an increase of the activity up to eleven times in diabetic rats. The concentrations of glycogen phosphorylase activity in insulin-treated diabetic rats after
15 days STZ treatment was similar to the values of control rats (see below). The glycogen phosphorylase activity measured in our preparations is negligible in the absence of AMP. However, $1 \mathrm{mmol} / \mathrm{l}$ AMP, a non-covalent allosteric activator of the $b$ form [35], produces a fast increase of the glycogen phosphorylase activity which is inhibited by $5 \mathrm{mmol} / \mathrm{l}$ caffeine, an inhibitor of the b form [36]. In conclusion, the glycogen phosphorylase in our preparations of SR-GL is the dephosphorylated form, both in control and diabetic rats, according to previous results with SR membranes from rabbit skeletal muscle $[11,37]$.

The presence of the dephosphorylated form of glycogen phosphorylase in our SR-GL preparations could be due, in part, to the protein phosphatases in SR-GL. It is known that the association of phosphorylase phosphatase activity with membranes of sarcoplasmic reticulum of skeletal muscle can occur [38, 39] and it has been shown that the PP1 activity in rabbit skeletal muscle associated with membranes (predominantly SR) is similar to that bound to glycogenprotein particles [13]. Because our original medium of preparation of SR-GL did not have inhibitors of protein phosphatases activity, we did a control experiment preparing SR-GL with and without protein phosphatase inhibitors in the medium of preparation. Our results show that the content of glycogen, glycogen phosphorylase and the glycogen phosphorylase activity are similar in both SR-GL preparations (data not shown). Also, the glycogen phosphorylase activity measured in the absence and presence of $2 \mu \mathrm{mol} / \mathrm{l}$ of okadaic acid, a potent inhibitor of PP1, is similar (data not shown). Thus, we can exclude the possibility of dephosphorylation of glycogen phosphorylase during the preparation of SR-GL.

Figure 2 shows a typical experiment in which different preparations of SR-GL were separated by SDS-PAGE: from control rats (lane 2), STZ-induced diabetic rats (lanes 3, 4 and 5) and STZ-induced insulin-treated diabetic rats (lane 6). The preparations of SR-GL in lanes 3, 4 and 5 were made at 7, 12 and 15 days after diabetic induction, respectively (Fig. 2 legend). We focused the study in two bands of interest: one of about 100000-105000 $\mathrm{M}_{\mathrm{r}}$ (see arrow) which corresponds to the $\mathrm{Ca}^{2+}$-ATPase (for comparative purposes, lane 1 contains intact SR vesicles from rabbit skeletal muscle), and the other centred at $97000 \mathrm{M}_{\mathrm{r}}$ (see double arrow) which is glycogen phos- 


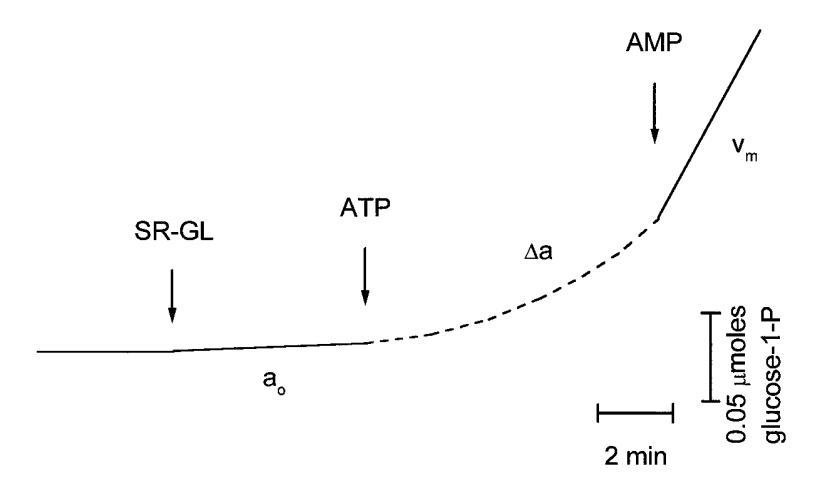

Fig. 1. Experimental approach used for determination of the rate of conversion of glycogen phosphorylase b to a. After addition of SR-GL, the little slope reflected phosphorylase a activity present in our preparations. This slope represented the $a_{0}$ parameter. The rate of phosphorylase $b \rightarrow a$ conversion is measured after adding $2 \mathrm{mmol}$ ATP. The dashed line represents the theoretical fit for $\Delta$ a calculation. ATP addition is considered as $\mathrm{t}=0$. Experimental data, plotted as $\mu$ mols of glucose-1-P production, were taken at different times after ATP addition. The addition of $1 \mathrm{mmol} / \mathrm{l}$ AMP allows the calculation of phosphorylase $b$ activity and of $V_{m}$ parameter

phorylase (compare with lane 7, standards, and see reference 11). It is clearly visible that the glycogen phosphorylase content is higher in preparations of SR-GL membranes from diabetic rats and that this content gradually rises upon the time of diabetic induction. The SR-GL prepared from insulin-treated diabetic rats (lane 6) shows a large decrease of the band centred at $97000 \mathrm{M}_{\mathrm{r}}$ (compared with lanes 3 to 5). Densitograms of lanes 2 to 6 (Fig.2) were made to measure the $\mathrm{Ca}^{2+}$-ATPase and glycogen phosphorylase bands (for quantification, an internal standard was taken). After normalization the ratio between $\mathrm{Ca}^{2+}$-ATPase bands in lanes 3, 4, 5 and 6 compared with lane 2 is about $1: 1$. On the contrary, the ratio between glycogen phosphorylase bands in lanes 3, 4, 5 and 6 compared with lane 2 were 3.7:1, 5.9:1, 6.7:1 and 1:1 respectively. Similar results were found with different preparations of SR-GL of control and diabetic rats.

In a previous study [11], we have shown that the amount of glycogen phosphorylase bound to SR membranes of rabbit skeletal muscle can be quantitatively measured using spectrophotometric and fluorimetric assays of the content of its coenzyme PLP. Using this approach we have measured the content of glycogen phosphorylase in preparations of SR-GL in both diabetic and insulin-treated diabetic rats at different times after STZ-diabetes induction (Fig.3A). We observed that the content of glycogen phosphorylase gradually increases with time after diabetes induction by STZ injection up to 15 days. We have measured the content of glycogen phosphorylase in SR-GL at 30 and 45 days of diabetes induction and

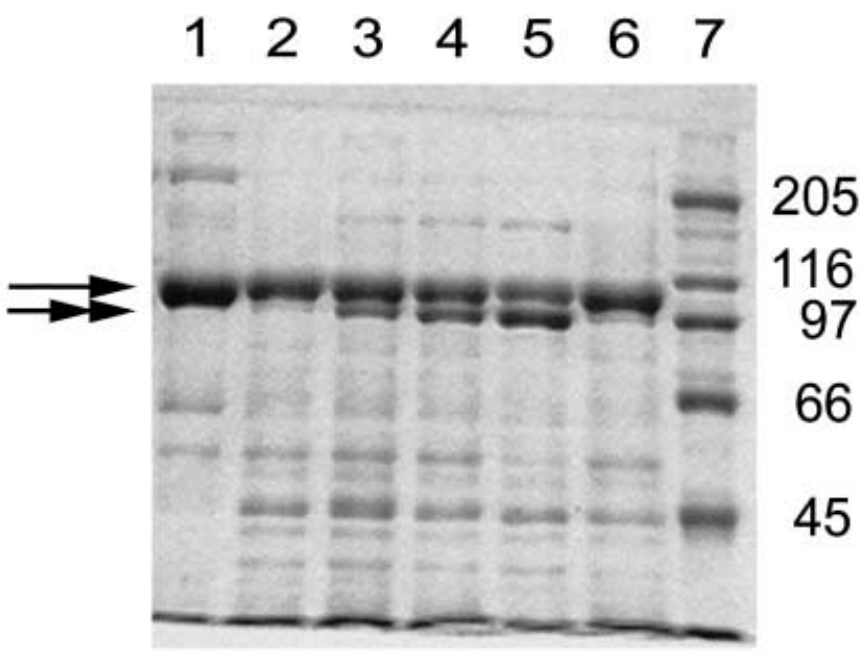

Fig. 2. SDS-PAGE of sarcoplasmic reticulum-glycogenolytic complex of control and diabetic rats. SDS-PAGE (using a $7.5 \%$ acrylamide Laemmli gel) was used to separate the proteins present in different SR-GL samples. Lane 1: SR vesicles of rabbit skeletal muscle (for comparative purposes). Lane 2: SR-GL of control rat skeletal muscle. Lanes 3, 4 and 5: SRGL of STZ-induced diabetic rat skeletal muscle at different times of diabetes induction: 7 days (lane 3), 12 days (lane 4) and 15 days (lane 5). Lane 6: SR-GL of insulin-treated diabetic rat skeletal muscle. Lane 7: molecular mass standards in Da [myosin (205000), $\beta$-galactosidase (116 000), glycogen phosphorylase (97000), bovine serum albumin (66000), ovoalbumin (45000) and carbonic anhidrase (29000)]. Fifteen micrograms of protein was loaded onto the gel in all lanes except for standard and lane 1

we have obtained the same value as at 15 days (not shown). Of interest, insulin treatment of diabetic rats reduced glycogen phosphorylase concentrations to control values. Figure 3B shows that the time-dependent phosphorylase activity present in SR-GL of diabetic and insulin-treated diabetic rats is similar to the time-dependent PLP content in SR-GL (Figure 3A).

In our previous studies $[11,12]$, we concluded that the glycogen in SR membranes plays a major part in the association of glycogen phosphorylase with these membranes. To determine if the increase of glycogen phosphorylase of SR-GL prepared from diabetic rats is also accompanied by an increase in the content of glycogen in these membranes, we measured the glycogen content in diabetic rats as described in Methods. Fig. 4 shows that SR-GL preparations from rats injected with STZ are shown to have a fivefold increase in glycogen content compared with the control rats. Additionally, insulin injections given to STZtreated rats reduced the glycogen content associated with the SR-GL membranes to values below the content found in control rats, as it has been observed for glycogen phosphorylase (see above).

To determine if the increase of glycogen is only seen in SR-GL preparations or, on the contrary, is also seen in total muscle, we measured the concentrations of glycogen in the total muscle tissue of the con- 


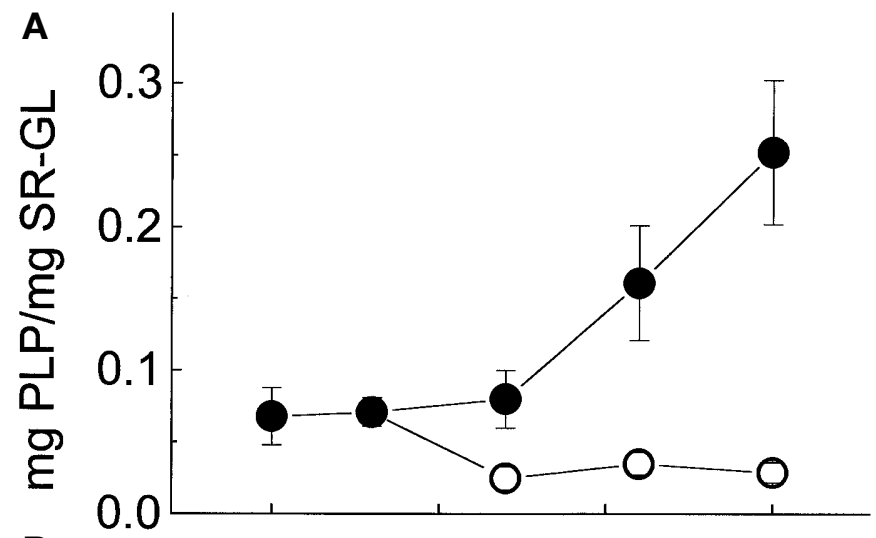

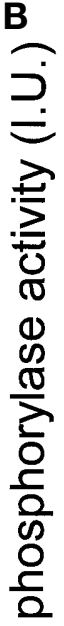

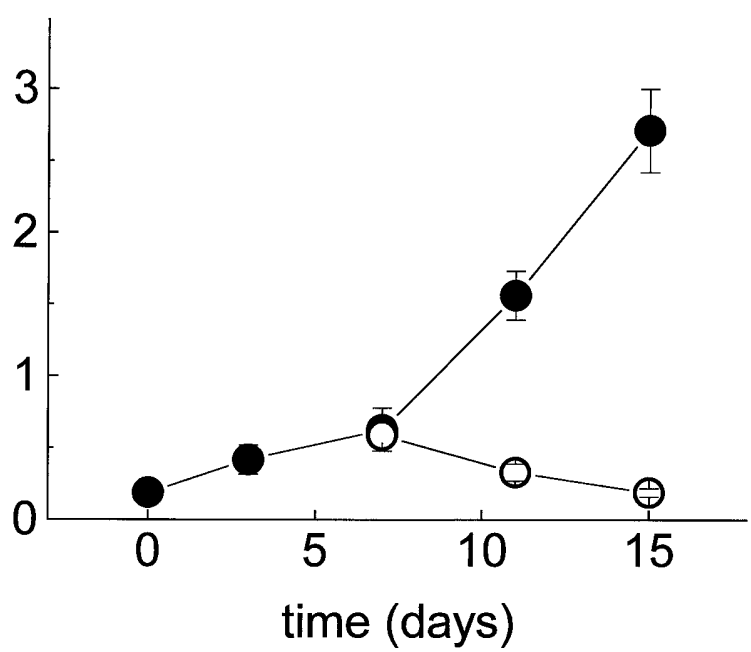

Fig. 3 (A, B). Time course of PLP content (A) and glycogen phosphorylase activity (B) in SR-GL prepared from skeletal muscle of STZ-induced diabetic rats (O) and insulin-treated STZ-induced diabetic rats $(\bigcirc)$. Symbols are the means \pm SEM of three preparations of SR-GL except for time 0 and 15 days which were ten and nine preparations of SR-GL, respectively. PLP content in SR-GL from control rats and diabetic rats 15 days after STZ injection were $0.068 \pm 0.020$ and $0.252 \pm 0.09 \mathrm{mg} \mathrm{PLP} / \mathrm{mg}$ SR-GL protein respectively. The difference among the group mean is very significant $(p=0.0029)$. Glycogen phosphorylase activity in SR-GL from control rats and diabetic rats 15 days after STZ injection were $0.19 \pm 0.04$ and $2.71 \pm 0.29$ I.U respectively. The difference among the groups means is highly significant ( $p$ value $<0.0001)$

trol and diabetic rats (Materials and methods). The results obtained were $24.1 \pm 1.4 \mu \mathrm{g}$ of glycogen per $\mathrm{mg}$ of muscle in control rats $(n=12)$ and $22.6 \pm 1.2 \mu \mathrm{g}$ of glycogen per $\mathrm{mg}$ of muscle in 15-day diabetic rats $(n=10)$, with no significant difference $(p<0.5$, ANOVA test). The amount of glycogen associated with SR-GL is thus a very small percentage of the total. Because the total muscle weight is reduced in diabetic rats (see above), total glycogen is also reduced in diabetic rats, probably contributing to reduced energy stores in the insulin deficient and poorly controlled diabetic animal.

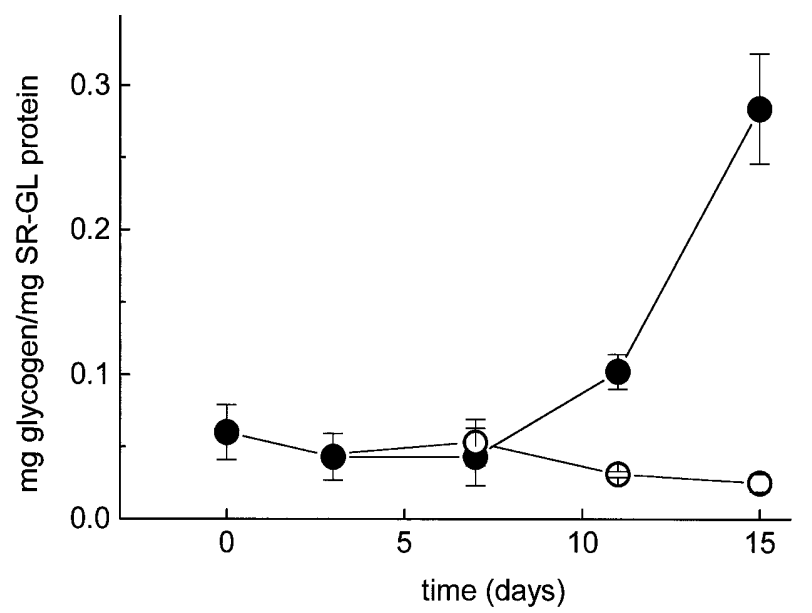

Fig. 4. Time course of glycogen content in SR-GL prepared from skeletal muscle of STZ-induced diabetic rats $(\mathbf{O})$ and from insulin-treated STZ-induced diabetic rats $(\bigcirc)$. Glycogen content in SR-GL from control rats $(n=10)$ and from diabetic rats 15 days after STZ injection $(n=9)$ were $0.060 \pm 0.019$ and $0.284 \pm 0.038 \mathrm{mg}$ glycogen $/ \mathrm{mg}$ SR-GL protein, respectively. The difference among the groups means is highly significant ( $p$ value $<0.0001$ ). The difference between the means of control group and of insulin treated rats $(0.025 \pm 0.006)$ was not significant

The relation between the change in glycogen phosphorylase content and the change in glycogen content in SR-GL complex of control and diabetic rats was significant and positive $(r=0.906 ; p<0.0001$, Fig. 5$)$.

As we have previously shown, the association of glycogen phosphorylase with the SR membranes is enhanced when the enzyme is in its dephosphorylated form, the inactive $b$ form $[12,37]$. Under diabetic conditions, we observed that glycogen phosphorylase is enhanced in the SR-GL complex. To determine if this increase is related to the conversion between both forms of glycogen phosphorylase, we measured the endogenous rate of transformation of glycogen phosphorylase $b$ to a in SR-GL from control and diabetic rats (Materials and methods). The phosphorylase kinase activity is a direct measure of the rate of transformation of glycogen phosphorylase $b$ to $a$. The phosphorylase kinase activity is approximately $50 \%$ lower in diabetic rats (Fig.6) suggesting that their glycogen phosphorylase is in the inactive $b$ form, facilitating the association with SR membranes.

\section{Discussion}

In this report we measured the activity of different enzymes related to carbohydrate metabolism associated with the SR-GL complex of skeletal muscle from diabetic and control rats. The only enzymes tested that showed a significant difference between both conditions were glycogen phosphorylase, which is approximately eleven times greater in SR-GL 


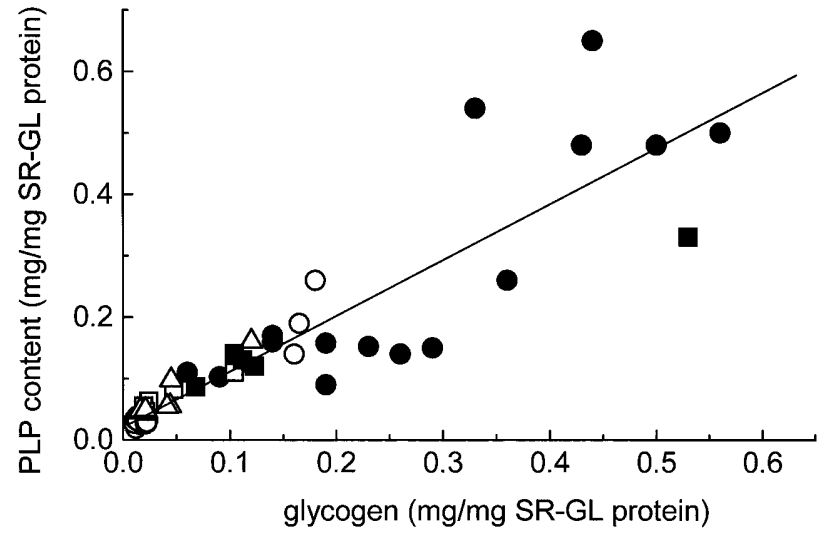

Fig. 5. Relation between glycogen phosphorylase content and glycogen content in 53 preparations of SR-GL from control and STZ-induced diabetic rats. The preparations of SR-GL were control $(\bigcirc)$ and STZ-induced diabetic rats at $3(\square), 7$ $(\Delta), 11(\square)$ and $15(\boldsymbol{O})$ days after STZ injection. The $r$ value for linear regression is 0.906

from diabetic rats than from control rats, and phosphorylase kinase, which shows half the value in diabetic animals. Because this increase in glycogen phosphorylase activity is probably caused by an increase in the glycogen phosphorylase associated with SRGL, we have focused this study on the effect of diabetes on the content of glycogen phosphorylase in preparations of SR-GL in skeletal muscle. We show an increase in the amount of the glycogen phosphorylase associated with SR-GL in insulin-dependent diabetic rats (Fig. 2, 3), in parallel with an increase of glycogen phosphorylase activity measured in $1 \mathrm{mmol} / \mathrm{l}$ of AMP ( phosphorylase b activity) (Fig. 3B). Treatment of diabetic rats with insulin reverses the effect observed, suggesting that the concentration of glycogen phosphorylase is under hormonal control. Also, there is probably an excessive insulin effect, as mentioned above. However, although the increase in the amount of glycogen phosphorylase is not known exactly, it is possible that an increase in the expression of specific mRNA could be related to this augmentation of glycogen phosphorylase. In this context, the effect of STZ-induced diabetes and insulin treatment on glycogen phosphorylase mRNA in rat skeletal muscle has been recently examined and glycogen phosphorylase mRNA was observed to be increased in diabetic rat muscle tissue, but partially suppressed after insulin treatment [5]. However, others have shown that in diabetic rat liver the concentrations of glycogen phosphorylase mRNA were lowered [4], a situation in which hepatic glucose production is increased due to enhanced glycogenolysis and glyconeogenesis. The increase of glycogen phosphorylase mRNA in skeletal muscle of diabetic rats supports that our results could be interpreted in terms of a rise in protein synthesis. However, we cannot rule out the possibility that degradation of glycogen phosphorylase is not al-

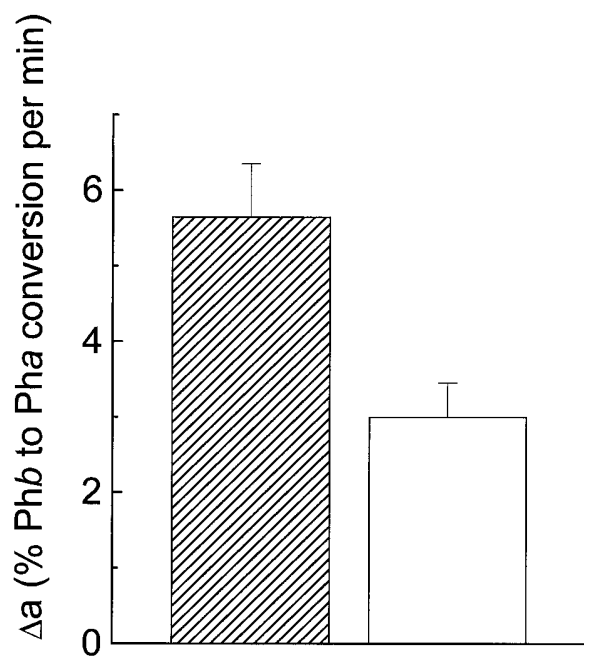

Fig. 6. Phosphorylase kinase activity in SR-GL from control and STZ-induced diabetic rats. The phosphorylase kinase activity was measured as the rate of transformation of glycogen phosphorylase $b$ to a. The measurements of glycogen phosphorylase $b$ to a conversion and of the glycogen phosphorylase $b$ activity were initiated by adding $2 \mathrm{mmol} / \mathrm{l}$ ATP and of $1 \mathrm{mmol} / 1 \mathrm{AMP}$, respectively

tered during the diabetic state. Therefore, the steady-state content of glycogen phosphorylase in our preparations of SR-GL can reflect a balance between degradation and synthesis.

In contrast it has been determined that SR membrane preparations contain glycogen $[12,39]$ and that enzymes related with the metabolism of glycogen with phosphorylase phosphatase activity (e.g. $\mathrm{PP} 1_{\mathrm{G}}$ ), might contribute to the long-recognized physical association of SR with glycogen [14]. In our previous studies [11,12], we concluded that the glycogen present in SR membranes plays a major part in the association of glycogen phosphorylase with these membranes, since (i) treatment with $\alpha$-amylase dissociates endogenous glycogen phosphorylase from SR membranes, and (ii) the inhibition of purified glycogen phosphorylase by SR membranes is due to an interaction with linear polysaccharide fragments associated with SR. In agreement with our previous results, we can conclude that the association of glycogen phosphorylase with SR-GL is mediated by a mechanism involving glycogen. It is known that in skeletal muscle glycogen synthesis is activated by insulin and the insulin concentrations in diabetic animals are lower. Therefore, we can deduce that the glycogen concentrations in diabetic animals are also decreased. However, we have shown that the content of total glycogen in muscle is approximately the same in diabetic and in control rats, with the content of glycogen in SR-GL clearly enhanced in diabetic rats. These data clearly suggest that only a minor percentage of the glycogen in diabetic muscle is relocalized in the SRGL, thus merely reflecting relocalisation of glycogen 
phosphorylase. To further support this view, we centred the analysis on glycogen biogenesis, which is controlled by a mechanism involving kinases and phosphatase activities. It is well established that phosphorylase kinase is the key enzyme regulating glycogen degradation, and that this enzyme is present in SR membranes [40] with a double function: (i) phosphorylation of glycogen phosphorylase b stimulating glycogen degradation and (ii) inactivation of glycogen synthase by phosphorylation. This regulation pathway can explain our results. We have shown that together with higher glycogen concentrations and glycogen phosphorylase $b$ in preparations of SR-GL complex of diabetic rats compared with control rats, the phosphorylase kinase activity is lower in diabetic rats by $50 \%$ compared with control rats (Fig. 6). If phosphorylase kinase activity is lower in SR-GL from diabetic rats, the degradation of glycogen in the complex is decreased because the production of glycogen phosphorylase a is lower whereas the glycogen synthase is kept in its dephosphorylated form promoting glycogen synthesis. Since the content and activity of glycogen phosphorylase in SR-GL is the same in the presence or absence of protein phosphatase inhibitors, we can exclude the possible contribution of protein phosphatases, such as $\mathrm{PP} 1_{\mathrm{G}}$, to the dephosphorylation of proteins that are bound to the SR-GL during the isolation procedure of SR-GL. Furthermore, this result could indicate that the glycogen phosphorylase was primarily dephosphorylated before cell lysis. The accumulation of the dephosphorylated form (inactive) of glycogen phosphorylase in preparations of SR-GL from muscle of diabetic rats, could help promote glycogen synthesis and thus could be a compensatory mechanism to maintain a base survival rate of glycogen synthesis. In addition, the association of glycogen phosphorylase with SR-GL increases threefold to fourfold the $\mathrm{K}_{0.5}$ for AMP activation of the dephosphorylated $b$ form of glycogen phosphorylase [12], therefore further potentiating this compensatory mechanism in skeletal muscle of the severely insulin-deficient diabetic animal.

We have previously shown $[18,19]$ that the association of glycogen phosphorylase b with SR-GL is important from a physiological point of view because the glycogen phosphorolysis can form a metabolic shuttle to support $\mathrm{Ca}^{2+}$ uptake by SR membranes. This metabolic shuttle can be sufficiently operating in vivo, particularly in conditions of metabolic energy depletion observed in diabetic animals, to prevent cellular death by cytosolic $\mathrm{Ca}^{2+}$ proteases.

Acknowledgements. We are very grateful to Drs A. Cuenda and D. Alessi for their helpful discussions and for their critical reading of the manuscript. We are grateful to A. Alonso for technical assistance. The study was supported by Grant SAF95-0262 of the Spanish Comision Interministerial de Ciencia y Tecnologia (CICYT) and by Grant PRI97C137 of the Junta de Extremadura.

\section{References}

1. Cohen P (1989) The structure and regulation of protein phosphatases. Annu Rev Biochem 58: 453-508

2. Cross D A, Watt P W, Shaw M et al. (1997) Insulin activates protein kinase B, inhibits glycogen synthase kinase-3 and activates glycogen synthase by rapamycin-insensitive pathways in skeletal muscle and adipose tissue. FEBS Lett 406: 211-215

3. Bahnat B R, Gold A H (1982) Effects of alloxan diabetes on the turnover of rat liver glycogen synthase. Comparison with liver phosphorylase. J Biol Chem 257: 8775-8780

4. Rao P V, Pugazhenthi S, Khandelwal RL (1995) The effects of streptozotocin-induced diabetes and insulin supplementation on expression of the glycogen phosphorylase gene in rat liver. J Biol Chem 270: 24955-24960

5. Reynet C, Kahn C R, Loeken M R (1996) Expression of the gene encoding glycogen phosphorylase is elevated in diabetic rat skeletal muscle and is regulated by insulin and cyclic AMP. Diabetologia 39: 183-189

6. Le Marchand-Brustel Y, Freychet P (1981) Regulation of glycogen synthase activity in the isolated mouse soleus muscle. Effect of insulin, epinephrine, glucose and anti-insulin receptor antibodies. Biochim Biophys Acta 677: $13-22$

7. Toth B, Bollen M, Stalmans W (1988) Acute regulation of hepatic protein phosphatases by glucagon, insulin and glucose. J Biol Chem 263: 14061-14066

8. Freymond D, Bogardus C, Okubo M, Stone K, Mott, D M (1988) Impaired insulin-stimulated muscle glycogen synthase activation in vivo in man is related to low fasting glycogen synthase phosphatase activity. J Clin Invest 82: 1503-1509

9. Kida Y, Esposito-del Puente A, Bogarduss C, Mott DM (1990) Insulin resistance is associated with reduced fasting and insulin-stimulated glycogen synthase phosphatase activity in human skeletal muscle. J Clin Invest 85 : 476-481

10. Miller T B Jr, Garnache A K, Cruz J, McPherson R K, Wolleben C (1986) Regulation of glycogen metabolism in primary cultures of rat hepatocytes. Restoration of acute effects of insulin and glucose in cells from diabetic rats. J Biol Chem 261: 785-790

11. Cuenda A, Henao F, Nogues M, Gutierrez-Merino C (1994) Quantification and removal of glycogen phosphorylase and other enzymes associated with sarcoplasmic reticulum membrane preparations. Biochim Biophys Acta 1194: 35-43

12. Cuenda A, Nogues M, Henao F, Gutiérrez-Merino C (1995) Interaction between glycogen phosphorylase and sarcoplasmic reticulum membranes and its functional implications. J Biol Chem 270: 11998-12004

13. Hubbard M J, Dent P, Smythe C, Cohen P (1990) Targetting of protein phosphatase 1 to the sarcoplasmic reticulum of rabbit skeletal muscle by a protein that is very similar or identical to the G subunit that directs the enzyme to glycogen. Eur J Biochem 189: 243-249

14. Hubbard M J, Cohen P (1993) On target with a new mechanism for the regulation of protein phosphorylation. Trends Biochem Sci 18: 172-177

15. Wanson J C, Drochmans P (1972) Role of the sarcoplasmic reticulum in glycogen metabolism. Binding of phosphorylase, phosphorylase kinase and primer complexes to the sarcovesicles of rabbit skeletal muscle. J Cell Biol 54: 206-224

16. Entman M L, Keslensky S S, Chu A, Van Winkle W B (1980) The sarcoplasmic reticulum-glycogenolytic com- 
plex in mammalian fast twitch skeletal muscle. Proposed in vitro counterpart of the contraction-activated glycogenolytic pool. J Biol Chem 255: 6245-6252

17. Goldstein M A, Murpha D L, van Winkle W B, Entman M L (1985) Cytochemical studies of a glycogen-sarcoplasmic reticulum complex. J Muscle Res Cell Motil 6: 177-187

18. Cuenda A, Nogues M, Gutierrez-Merino C, de Meis L (1993) Glycogen phosphorolysis can form a metabolic shuttle to support $\mathrm{Ca}^{2+}$ uptake by sarcoplasmic reticulum membranes in skeletal muscle. Biochem Biophys Res Commun 196: 1127-1132

19. Nogues M, Cuenda A, Henao F, Gutierrez-Merino C (1996) $\mathrm{Ca}^{2+}$ uptake coupled to glycogen phosphorolysis in the glycogenolytic-sarcoplasmic reticulum complex from rat skeletal muscle. Z Naturforsch 51: 591-598

20. Xu K Y, Zweier J L, Becker L C (1995) Functional coupling between glycolysis and sarcoplasmic reticulum $\mathrm{Ca}^{2+}$ transport. Circ Res 77: 88-97

21. Xu K Y, Becker L C (1998) Ultrastructural localization of glycolytic enzymes on sarcoplasmic reticulum vesicles. J Histochem Cytochem 46: 419-427

22. Gutierrez-Merino C, Molina A, Escudero B, Diez A, Laynez J (1989) Interaction of the local anesthetics dibucaine and tetracaine with sarcoplasmic reticulum membranes. Differential scanning calorimetry and fluorescence studies. Biochemistry 28: 3398-3406

23. Gutierrez-Merino C, Garcia-Blanco F, Pocovi M, Menendez M, Laynez J (1980) Regulation of phosphorylase b by AMP. The effects of enzyme concentration. J Biochem (Tokyo) 87: 1483-1490

24. Lowry O H, Rosebrough N J, Farr A L, Randall R J (1951) Protein measurement with the Folin phenol reagent. J Biol Chem 193: 265-275

25. Strausbauch P H, Kent A B, Hedrick J L, Fischer E H (1967) Preparation of reduced phosphorylase by use of sodium borohydride. Methods Enzymol 11: 671-675

26. Dubois M, Gilles K A, Hamilton J K, Rebers P A, Smith F (1956) Colorimetric method for determination of sugars and related substances. Anal Chem 28: 350-356

27. Brodal B P, Gehrken B B (1986) Enzymatic microanalysis of glycogen. Scand J Clin Lab Invest 46: 193-195

28. Cuenda A, Henao F, Gutierrez-Merino C (1990) Distances between functional sites of the $\mathrm{Ca}^{2+}+\mathrm{Mg}^{2+}$-ATPase from sarcoplasmic reticulum using $\mathrm{Co}^{2+}$ as a spectroscopic ruler. Eur J Biochem 194: 663-667

29. Laemmli U K (1970) Cleavage of structural proteins during the assembly of the head of bacteriophage T4. Nature 227: 680-685

30. Krebs E G (1966) Phosphorylase b kinase from rabbit muscle. Methods Enzymol 8: 543-546

31. Thieleczek R, Behle G, Messer A, Varsanyi M, Heilmeyer L M G Jr, Dreneckhahn D (1987) Localization of phosphorylase kinase subunits at the sarcoplasmic reticulum of rabbit skeletal muscle by monoclonal and polyclonal antibodies. Eur J Cell Biol 44: 333-340

32. Varsanyi M, Gröschel-Stewart V, Heilmeyer L M G Jr (1978) Characterization of a $\mathrm{Ca}^{2+}$-dependent protein kinase in skeletal muscle membranes of I-strain and wildtype mice. Eur J Biochem 87: 331-334

33. Cohen P (1973) The subunit structure of rabbit-skeletalmuscle phosphorylase kinase, and the molecular basis of its activations reactions. Eur J Biochem 34: 1-14

34. Jennissen H P, Heilmeyer L M G Jr, (1974) An automated assay for phosphorylase kinase. Anal Biochem 57: 118-126

35. Barford D, Hu S H, Johnson L N (1991) Structural mechanism for glycogen phosphorylase control by phosphorylation and AMP. J Mol Biol 218: 233-260

36. Vereb G, Fodor A, Bot G (1987) Kinetic characterization of rabbit skeletal muscle phosphorylase ab hybrid. Biochim Biophys Acta 915: 19-27

37. Cuenda A, Centeno F, Gutierrez Merino C (1991) Modulation by phosphorylation of glycogen phosphorylase-sarcoplasmic reticulum interaction. FEBS Lett 283: 273-276

38. Meyer F, Heilmeyer L M G, Haschke R H, Fischer E H (1970) Control of phosphorylase activity in a muscle glycogen particle. I. Isolation and characterization of the protein-glycogen complex. J Biol Chem 245: 6642-6648

39. Wanson J C, Drochmans P (1968) Rabbit skeletal muscle glycogen. A morphological and biochemical study of glycogen B-particles isolated by the precipitation-centrifugation method. J Cell Biol 38: 130-150

40. Polishchuk S V, Brandt N R, Meyer H E, Varsanyi M, Heilmeyer L M G Jr (1995) Does phosphorylase kinase control glycogen biosynthesis in skeletal muscle? FEBS Lett 362: 271-275 